\title{
Turismo cultural como experiencia educativa de ocio
}

\author{
Gabriela Orduna* \\ Carmen Urpí ${ }^{* *}$
}

\begin{abstract}
Resumen: Posiblemente el turismo es una de las pocas actividades humanas que encierra la ambivalencia de ser a la vez, negocio y ocio. Habitualmente, es analizado en la primera perspectiva como sector productivo y en pocas ocasiones se hace referencia a este concepto desde el punto de vista del ocio. Menos aun, se ahonda en la idea de que por ser una actividad de ocio tiene una dimensión educativa. Por ello, y desde esa reflexión pedagógica, se plantea este artículo, como una aproximación conceptual a la experiencia educativa para el turista, para el profesional anfitrión y para la comunidad de recepción que encierra una modalidad concreta del turismo, la cultural.

desarrollo local.

Palabras clave: turismo, patrimonio cultural, ocio creativo, educación,
\end{abstract}

\section{Cultural tourism as an educational experience of leisure}

\begin{abstract}
Tourism is probably one of the fewest human activities that include together both meanings: otium and negotium; thus it is related to leisure and productivity at the same time. Normally, it is analysed and studied as a productive object but in very few occasions it is mentioned as a leisure experience. And less, indeed, is said about the fact that tourism contains an educational dimension because of its consideration as a leisure experience. From this pedagogical point of view, the present article pretends to introduce a conceptual explanation about the educational experience that, specially, cultural tourism means for all the people involved in it: the visitor; the host professional; and finally, the community that welcomes the tourists.
\end{abstract}

Keywords: tourism, cultural heritage, education and serious leisure, local development.

\section{O turismo cultural como uma experiência educativa de lazer}

Resumo: Possivelmente o turismo é uma das poucas atividades humanas que incorpora a ambivalência de ser, ao mesmo tempo, negócio e lazer. Habitualmente, é analisado na primeira perspectiva como um setor produtivo, e raramente são feitas referencias a este conceito a partir do ponto de vista do lazer. Menos ainda, se investiga a ideia de que por ser uma atividade de lazer, tem uma dimensão

\footnotetext{
*Universidad de Navarra. Pamplona. España. Email: mgorduna@unav.es

** Universidad de Navarra. Pamplona. España. Email: curpi@unav.es
} 
educativa. Assim, partindo dessa reflexão pedagógica, este artigo é desenvolvido como uma aproximação conceitual à experiência educativa para o turista, para o profissional anfitrião e para a comunidade receptiva envolvida com uma modalidade concreta do turismo, a cultural.

Palavras-chave: turismo, patrimônio cultural, lazer criativo, educação, desenvolvimento local.

Recibido: 28.04.2010

Aceptado: 30.06.2010

$* * *$

\section{Turismo, ocio creativo y educación}

A modo de introducción y con el afán de no alargarnos demasiado en disquisiciones teóricas preliminares, queremos aportar aquí la cita de uno de los autores españoles que más páginas ha dedicado a la relación entre la educación y la cultura desde el ámbito de la pedagogía y de la educación social. Sus palabras nos resultan suficientemente clarificadoras y sugerentes para poder iniciar nuestro artículo sentando las bases de la relación existente entre la educación y la cultura.

"Todas las instituciones llamadas educativas son, por el mismo hecho de serlo, instituciones culturales; y lo mismo a la inversa. Si acaso, la diferencia entre unas y otras es sólo una diferencia de énfasis: las instituciones educativas ponen el acento en la transmisión o adquisición de la cultura, mientras las denominadas culturales lo ponen en la conservación (material), creación y uso de la cultura. Pero eso sólo es una diferencia de énfasis, ya que en las instituciones educativas además de la transmisión también hay elaboración y uso de la cultura. Y, por el otro lado, tampoco nadie negará que en las instituciones culturales existe también transmisión y aprendizaje. En definitiva, las unas se fijan más en unos determinados momentos del proceso cultural y las otras en otros, pero el objeto con el que ambas trabajan es justamente el mismo”. (Trilla, 2000: 135-136).

Desde esta perspectiva, el turismo cultural, como fenómeno que pone en relación las demandas e intereses de las personas con los bienes culturales que la sociedad quiere preservar, adquiere un interés especial para el análisis y la reflexión pedagógica que pretendemos desarrollar en el presente artículo.

Posiblemente una de las definiciones más citadas para explicar el concepto del turismo es la lanzada por la Organización Mundial del Turismo (OMT) de las Naciones Unidas ${ }^{1}$ en 1994, según la cuál el turismo com-

\footnotetext{
${ }^{1}$ La Organización Mundial del Turismo (OMT) es un organismo especializado de las Naciones Unidas y representa la principal institución internacional en el campo del turismo. Constituye un foro mundial para debatir cuestiones de política turística y una fuente útil de conocimientos especializados en este campo: http://www.world-tourism.org
} 
prende las actividades que hacen las personas durante sus viajes y estancias en lugares distintos a su entorno habitual, por un período consecutivo inferior a un año, con fines de ocio, por negocios o por otros motivos. Al no tratarse de una conceptualización académica, y estar diseñada fundamentalmente para el análisis estadístico de los movimientos turísticos y su repercusión económica, presenta algunas carencias e incluso aspectos cuestionables desde una perspectiva socio-económica como las posibilidades que encierran los entornos habituales y próximos al viajero en tanto que destino turístico; las oportunidades efectivas que tienen las personas de realizar un viaje por condicionantes económicos, sociales, políticos e incluso religiosos o la supeditación de los viajes a una medida temporal tan concreta como un año. Sin duda, se trata de un necesario y apasionante debate, que excede la intencionalidad de una reflexión que como la nuestra se ha concentrado en la educación. Desde la perspectiva pedagógica, y pensando en las personas que planean o realizan una actividad turística (esto es, desde la demanda) se abre también un campo muy interesante que tiene que ver con la posibilidad de educar la voluntad del viajero (su intención y su motivación), independientemente de su proximidad al destino elegido, el tiempo que dura el viaje o el motivo del desplazamiento.

Cuando la motivación del turismo proviene de querer disfrutar de una experiencia auténtica de ocio, podemos afirmar que lleva implícita una intencionalidad educativa. Para entender esta conexión entre turismo, ocio y educación, puede ayudar acudir a un concepto contemporáneo de ocio (Pieper, 2003) que recupera la raíz epistemológica (scholé) proveniente de la teoría aristotélica, por la cual el ocio significa “pararse”, desocuparse, en contraposición a estar ocupado o pre-ocupado. Por tanto, más que a una medición cuantitativa de tiempo libre se refiere a una actitud de reposo y de paz con uno mismo, a un estar liberado de la necesidad de estar ocupado y poder dedicarse así a la formación (cabe puntualizar que scholé también da origen a la palabra “escuela”).

Sin pretender ahondar aquí en este concepto teórico, sí nos interesa al menos rescatar su aspecto más esencial, por el cual el ocio se define no tanto como una cantidad de tiempo libre de obligaciones sino, más bien, como una cualidad. Esta distinción nos permite reflexionar sobre las contradicciones y tensiones existentes en torno a la vivencia del ocio en nuestras sociedades actuales.

En primer lugar, cabría distinguir entre ocio y tiempo libre: mientras el concepto de "tiempo libre” hace referencia al aspecto más cuantitativo del tiempo desocupado, el concepto de “ocio” se refiere sobre todo a la actitud interior o vivencia cualitativa. Varios autores a lo largo de la investigación sobre el ocio han incluido en esta vivencia unos rasgos diferenciadores, entre los que destacarían: su carácter libre, placentero y desinteresado (Dumazedier, 1962; Cuenca, 2004; Puig Rovira y Trilla, 1987).

Esta primera diferenciación nos lleva a considerar la distancia que, desde una perspectiva educativa como la aquí adoptada, se puede percibir 
entre lo deseable y lo existente. Una cosa es plantear un concepto ideal de ocio y otra es la realidad que se vive en nuestras diferentes culturas y sociedades, en las que abundan prácticas de ocio estandarizado, pasivo o, incluso, nocivo desde el punto de vista de un crecimiento sano y feliz. Generalmente, las teorías educativas funcionan desde intencionalidades que apuntan hacia fines a conseguir, pero conviene que partan de las distintas realidades concretas en que van a ser aplicadas para que la actuación educativa correspondiente sea realmente efectiva y para que no acaben convertidas en meras fórmulas ideales e ineficaces, desligadas de la problemática concreta de cada sociedad y cultura.

Por otro lado, en segundo lugar, actualmente la creciente comercialización del ocio y la actitud consumista predominante en nuestra sociedad global hacen del concepto de ocio mencionado un objetivo difícil de alcanzar. Los estudios estadísticos que describen las costumbres de ocio más habituales entre el consumidor medio indican que la oferta estándar y mayoritaria de ocio puede estar condicionando desfavorablemente las posibilidades de libre elección. Además, esto mismo puede redundar en la disminución del placer o calidad del ocio, por el carácter impersonal y superficial que adquiere cuando la oferta se dirige a satisfacer los aspectos más generales de un público que es considerado homogéneamente. De ahí que buena parte de los productos que se ofertan vayan más en la línea de la evasión que de la interiorización, del pasatiempo que del conocimiento, o del consumo pasivo que del cuidado y de la valoración del entorno, de la cultura, o del mundo, en general.

Por último, y en tercer lugar, existe también otro riesgo típico en las prácticas de ocio actuales que responde a una actitud utilitarista o productivista, criticada por Weber ya en 1963, que acentúa la persecución de un resultado, beneficio, provecho o interés posterior a la propia actividad de ocio, por encima de la satisfacción que se obtiene, a la hora de su elección. Por ejemplo, hacer deporte para bajar peso, aprender inglés para mejorar las posibilidades de trabajo, etc. Sin menospreciar la conveniencia de estas elecciones, cabría advertir que el hecho dar prioridad al resultado perseguido puede desequilibrar la vivencia desinteresada de ocio.

En conclusión, advertimos, desde nuestra perspectiva del ocio entendido como experiencia libre, placentera y desinteresada, la posibilidad de autorrealización personal en los individuos; es decir, la posibilidad de crecimiento personal o de educación, entendida ésta en sentido amplio, no como mera instrucción de ideas y preceptos sino como crecimiento y mejora continuada de las personas en sus distintas posibilidades. Desde un análisis pedagógico, podemos advertir modalidades distintas de experiencias de ocio según el aspecto de la actividad que se vea resaltado, dentro de las cuales se encuentran las referidas al turismo cultural. Siguiendo la diferenciación básica establecida por Cuenca (2004)² para explicar las distintas

\footnotetext{
${ }^{2}$ Según este autor, el ocio posee, en primer lugar, una dimensión lúdica que lo caracteriza por su estrecha conexión con el juego, en cuanto al fin recreativo y placentero que persigue
} 
dimensiones educativas del ocio, el turismo cultural se situaría entre las posibles experiencias de ocio creativo.

Lógicamente, en las experiencias de ocio podemos vivir múltiples aspectos, en mayor o menor medida; sin embargo, en el ocio que se busca por medio del turismo cultural destacan, sobre todo, los aspectos creativo, ambiental y social, debido al carácter específico de esta experiencia que requiere, respectivamente, la participación activa del sujeto, un lugar señalado y una actitud relacional y comunicativa; también el aspecto vacacional vivenciado a menudo en la experiencia turística cultural añade un carácter lúdico y festivo a considerar.

La actitud abierta y la disposición participativa del turista que acude al encuentro con la cultura como algo vivo y busca entusiasmarse en el descubrimiento y el diálogo con ella, favorece un tipo de ocio creativo. Desde una perspectiva pedagógica, se pueden promover condiciones favorables para que el turista no se sitúe pasivamente frente al bien cultural como mero receptor de información sino que, más bien, se acerque con la curiosidad y la motivación que le conducen a interesarse y a dialogar con la realidad cultural que visita, de modo que pueda disfrutar del turismo cultural como una experiencia de ocio que es, a la vez, satisfactoria y formativa.

Por otra parte, desde la posición de la comunidad anfitriona que oferta la experiencia educativa de turismo cultural podríamos coincidir con entidades como Naciones Unidas que asignan una alta prioridad a la formación en los programas de Desarrollo Humano, con lo que consiguen estimular las capacidades de la población local y dinamizar el entorno en el que surgen las iniciativas.

Los contenidos de la formación cultural permiten a la comunidad una mejor relación con su legado histórico en la medida en que su objetivo es facilitar la valoración y apreciación de las obras culturales y artísticas ya existentes; pero también busca fomentar la creación de nuevos valores y nuevas obras, aprovechando las capacidades de cada persona (Paz, 1984: 50-53). Así entendemos que aprender a convertir un elemento cultural en un elemento turístico es una re-creación cultural que debe encontrar su sentido desde y en la propia cultura local. De tal manera que, la formación deberá favorecer las formas de expresión propias de cada persona y cada

en su propia realización; en segundo lugar, posee una dimensión ambiental que resalta la actividad por el entorno inmediato en el cual se desenvuelve (visitar las calles de una ciudad histórica, por ejemplo); además, el ocio también posee una dimensión creativa en quien lo realiza no como mero receptor pasivo sino como sujeto activo que participa e interactúa con la realidad experimentada (es sobre todo en este sentido de creatividad que hablamos del ocio como experiencia de autorrealización y satisfacción personal); puede también el ocio poseer una dimensión festiva, cuando la vivencia afirma la alegría vital del sujeto que la experimenta; y, por último, cuando se comparte con otros, el ocio adquiere una dimensión social, solidaria o comunitaria, en el sentido de que el encuentro con otros se vuelve el centro de la experiencia de ocio. 
grupo a partir de sus experiencias de vida y sus valores específicos (UNESCO, 1977: 253).

Es decir, la identidad cultural es lo que permite a los individuos sentirse como integrantes de una comunidad, reconociéndose entre sujetos como equivalentes o similares en tanto que copartícipes de la cultura (AnderEgg, 1989: 236). Cada sujeto, en ese proceso de identificación, debe recibir formación para asumir su propia cultura (conocerla, valorarla y apreciarla) y ser, al mismo tiempo preparado para una creación cultural que le permita resolver problemas locales con los propios recursos e incluso para recrear su cultura y generar nuevos productos e interpretaciones que ofrecer a turistas y visitantes

Por otra parte, aquellos que están más directamente implicados en el turismo ven con mejores ojos la actividad, mientras quienes están al margen de la actividad y no le ven la repercusión directa son más ambivalentes o, en algunos casos, contrarios hacia el turismo; entonces, la labor de sensibilización de esa parte de la población “más distante” tendría un alto componente pedagógico.

Toda esta formación, esta preparación para el aprovechamiento de los recursos patrimoniales por la comunidad anfitriona, propicia una mejora cultural (Ander-Egg, 1989: 162). La formación cumple, de este modo, una función social al fomentar el enraizamiento de la población en su cultura; al impulsar nuevas actitudes hacia el cambio social, el compromiso y la acción y al consolidar redes de solidaridad (Jover, 1990: 21).

La formación de la comunidad anfitriona en materia de turismo cultural, presenta dos tipos de sujetos bien diferenciados para la atención pedagógica: la comunidad en general, para la que adopta, especialmente, carácter de sensibilización y descubrimiento de los elementos culturales en clave de recurso económico y la de los profesionales que atenderán la oferta turística a través de una recreación turística, y cultural, de elementos propios de la identidad cultural.

Revisada hasta aquí brevemente, a modo introductorio, la relación existente entre el turismo, el ocio y la educación, nos adentramos a continuación en el tipo específico de turismo que nos ocupa, el cultural, y en la relación que guarda con la educación propiamente orientada a los bienes culturales del patrimonio humano, también denominada educación patrimonial.

\section{Turismo y Patrimonio Cultural}

Cuando en la literatura se hace referencia a los objetivos del turismo cultural se enumeran, entremezcladas, diferentes intenciones, casi todas referidas a la comunidad donde se sitúa el bien patrimonial, y así se apunta como misiones de éste: 
“crear empleo; fomentar el arraigo rural; revalorizar el patrimonio cultural; desarrollar una oferta no concertada, de pequeña escala y con valor agregado; y fomentar el asociativismo basado en la necesidad de lograr un mejor acceso a la promoción, la comercialización, la capacitación, la compra de insumos y a las fuentes de financiación y asesoramiento en los distintos aspectos (contable, legal, gastronomía, alojamiento, etc.)” (Toselli 2006: 177).

En este sentido, no podemos obviar que los aspectos económicos del turismo son fundamentales, menos aun ignorar que la riqueza generada por la explotación turística de ciertos elementos culturales se reparte de manera dispar entre la población anfitriona pudiendo ser causa de desigualdades sociales o económicas; ni se nos puede escapar tampoco el hecho de que esa misma explotación de los recursos culturales puede llegar a pervertirlos, degradarlos o alterarlos. Sin duda, son reflexiones muy necesarias para mejorar el turismo como fenómeno social y económico, pero entendemos que estos análisis deben ser abordados científicamente desde la consideración de otras ciencias y disciplinas académicas como la sociología, la psicología o la economía, la historia o la política. La pedagogía guarda una estrechísima relación con todas ellas y una interesante posibilidad de aportación a la reflexión transdisciplinar, pero también tiene su campo propio de reflexión e investigación académica. En nuestro discurso, elegimos como hilo conductor el centrarnos en las oportunidades pedagógicas que el turismo cultural presenta.

Así, en el apartado siguiente nos referimos al turismo cultural como demanda educativa y de ocio creativo por parte de los propios turistas y visitantes; en segundo lugar, en el apartado 4, tratamos desde el punto de vista de los profesionales del turismo cultural el tipo de oferta educativa que éste genera; por último, en el apartado 5, revisaremos los beneficios que supone para la población anfitriona la promoción del turismo cultural como actividad de ocio creativo.

Pero antes de abordar esta triple perspectiva interesa introducir algunas ideas generales acerca del patrimonio cultural y su relación con la educación, para entender la conexión que se pretende defender en estas páginas entre el turismo cultural y la educación del ocio. Para ello, conviene advertir en primer lugar cómo recientemente la idea de la educación patrimonial ha ido adquiriendo mayor presencia en el panorama cultural actual. Son numerosas las instituciones culturales referidas a algún bien patrimonial que han ido incorporando por medio de sus plantillas de profesionales y de sus programas de actividades, algunas cuestiones importantes relacionadas con la educación. Del mismo modo, van apareciendo iniciativas de formación en este sentido que perfilan cada vez más la figura profesional del educador patrimonial, aunque todavía es necesario aumentar los cauces de participación y de formación de estos agentes sociales de manera que puedan atender la diversidad de demandas según las necesidades específicas que presenten. La realidad demuestra que los intereses y los puntos de partida de las diferentes personas, grupos o 
colectivos beneficiarios de una experiencia de turismo cultural difieren notablemente y que, por ello, los agentes socioeducativos deben tener la preparación y la sensibilidad necesarias para generar una oferta diversificada, motivadora, orientadora, preventiva o promotora de una toma de conciencia acerca de los beneficios personales que cada uno puede encontrar en el turismo cultural, en particular, y en el ocio, en general (Mundy y Odum, 1979).

Dichas actuaciones no deberían ser ajenas a las problemáticas existentes en la misma sociedad en que se generan. Los cambios filosóficos, sociales y culturales introducidos por la posmodernidad afectan también a la idea de patrimonio, de cultura y de arte. La ruptura de la posmodernidad con respecto a la idea moderna de modelos universales ha conducido, por un lado, a la apertura y al reconocimiento de la validez múltiple de referentes culturales distintos, accesibles para todos y no únicamente para una élite formada en una determinada tradición (Efland, Freedman \& Stuhr, 2003: 77-78), pero, por otro lado, ha provocado también paradójicamente la incomprensión y el alejamiento de las personas con respecto a las nuevas creaciones culturales y artísticas. Esta confusión y desorientación sobre qué merece ser valorado y conservado como patrimonio humano reclama la intervención de la educación para facilitar la adquisición de nuevas claves que permitan el acceso de todos a un patrimonio considerado como algo colectivo (Fontal, 2003:11). Pero, desde la pedagogía ¿cabe pensar que nos encontremos de nuevo ante una situación análoga a la tan anteriormente criticada por la posmodernidad? Ciertamente, la revisión crítica de los paradigmas existentes es un requisito indispensable para el progreso científico y cultural, pero puede resultar arriesgado condenar sistemáticamente los referentes modernos y clásicos de la cultura para acabar absolutizando las nuevas claves posmodernas.

Por otro lado, la amenaza de que las instituciones dedicadas a la cultura quedasen relegadas a una mera función de conservación, desligadas del gran público como espacios sociales y fueran utilizadas sólo por especialistas, levantó varias voces para reclamar el carácter de difusión y formación de este tipo de instituciones; en definitiva, la idea de servicio social que debían prestar (Olofson, 1979: 11-13; Valdés, 1999: 11; HooperGreenhill, 1998: 9-11). Una de las primeras referencias al respecto fue la recomendación de la UNESCO en la Convención sobre la Protección del Patrimonio Mundial, Cultural y Natural, celebrada en París en 1972, para que los estados miembros pusieran en marcha programas de educación y difusión para fomentar el respeto, la valoración y sensibilización hacia el patrimonio entre los habitantes de su territorio (Fontal, 2003: 96-97). Además, esta idea apareció asociada al fomento de identidades nacionales a través del conocimiento de la historia de cada país, de manera que se subrayaba la importancia de la cultura para promover la participación social de la ciudadanía, la responsabilidad civil y la capacitación en los procesos democráticos. En el año 1974, el Internacional Council of Museums (ICOM) también definió la educación como uno de los fines prioritarios de los museos. 
Cabe deducir, por tanto, que la iniciativa educativa sobre el patrimonio humano surge de las propias instituciones culturales y artísticas, y no tanto de las instituciones educativas, de manera que la educación patrimonial empieza a desarrollarse, cronológicamente en el tiempo, en el ámbito no formal e informal de la educación, mientras la inserción dentro del sistema formal de enseñanza ha tenido que esperar más tiempo y todavía hoy deja bastante que desear, puesto que la idea de la educación patrimonial como contenido curricular aparece solo implícitamente en las distintas disciplinas que integran el saber humano: la historia, la literatura, el arte, los idiomas, la naturaleza, etc.

Entonces, puesto que la mayoría de los profesionales que trabajan en las propias instituciones culturales provenían del ámbito de la historia del arte, de la animación sociocultural, de las relaciones públicas, y no tanto del ámbito de la pedagogía o la educación social, su formación sufría de ciertas lagunas con respecto al manejo educativo del nuevo carácter atribuido de servicio social.

También la investigación sobre la educación patrimonial se ha realizado, hasta ahora, desde instancias más cercanas al mundo del arte y la cultura que desde las que pertenecen al ámbito de la pedagogía y la educación social. Por ello, como es de suponer dada la perspectiva pedagógica adoptada en este trabajo, resulta prioritario fomentar la investigación científica sobre temas relacionados específicamente con la formación y la difusión del patrimonio, promoviendo dentro de lo posible un marcado carácter interdisciplinar entre pedagogos, historiadores, sociólogos, estetas, etc. El panorama que se abre para el análisis pedagógico es muy amplio, y para delimitar esta reflexión hemos elegido centrarnos en los protagonistas de la educación patrimonial, empezando por aquellos que demandan cultura en su tiempo de ocio turístico.

\section{Turismo Cultural como demanda educativa y de ocio creativo}

Cuando un viajero elige un destino cultural tiene una clara intención de aprender de esta experiencia. El contenido del viaje puede ser muy variado pero siempre precisa de recursos histórico-artísticos para su desarrollo y puede adoptar múltiples fórmulas combinables entre sí. La gama de contenidos del turismo cultural es tan amplia como diversas y complejas son las manifestaciones de la cultura en cada destino turístico, y así cabe hablar de turismo Urbano (desde el turismo desarrollado en ciudades Patrimonio de la Humanidad, donde el atractivo es todo el conjunto urbano hasta poblaciones que cuentan, de antiguo o no, con un elemento cultural tractor de gran envergadura que les convierte en ciudades culturales); Monumental, arqueológico, funerario; Etnográfico; Artístico (motivado por lugares o eventos de carácter musical, pictóricos, literarios, bibliográfico, hasta biográfico e incluso literarios espacios inventados); Cientí- 
fico (donde el destino está en estaciones biológicas, yacimientos arqueológicos, vinculado a personajes científicos); Gastronómico y enológico; Industrial (motivado por la visita a fábricas o grandes construcciones civiles); Religioso y Místico (lugares energéticos, sitios emblemáticos o de peregrinación para alguna religión).

En realidad como todo lo que ha generado y genera el ser humano tiene entidad cultural, el debate que se abre aquí está en el valor que ese elemento cultural puede tener desde su diferente consideración como recurso patrimonial, turístico y pedagógico.

Centrándonos en ese valor educativo, la experiencia que busca el turista va más allá de una actividad cultural o lúdica, se trata de disfrutar del tiempo libre acercándose a una identidad cultural, un lugar, una historia, un pueblo o un monumento para aprender algo de ella, aspirando a su enriquecimiento personal. En este sentido, caben muchas maneras de conocer, por ejemplo, un monumento: investigar en la bibliografía, acudir a una conferencia o visitarlo mediante la ayuda de un guía local. Por lo general, los turistas que suelen acudir a estas visitas no esperan encontrar un especialista o experto en determinado estilo arquitectónico, sino alguien que interprete ese monumento para "darle vida" a través del resalte de sus peculiaridades, de las diferencias, de aquello que distingue a ese monumento de otros de la misma época, ya sea sus diferencias arquitectónicas, sus vicisitudes históricas, sus anécdotas o sus leyendas. En este sentido, cabe decir, que desde la propuesta al visitante, la experiencia pedagógica del turismo cultural necesita que la propia identidad cultural de cada destino se convierta en los contenidos de las propuestas.

El viajero espera una experiencia singular y la ocasión de vivir un momento diferente que tendría que ser presentado, entre otras cosas, como atractivo, estimulante, sugerente y divertido para que lo pudiéramos incluir en la categoría de las actividades de ocio.

Las propuestas de interpretación de estos contenidos al visitante pueden ser muy variadas desde la mera exposición donde el viajero simplemente escucha y mira, a actividades que pueden buscar la implicación y participación del público a través del uso de otras sensaciones: tocar, sentir, oler, degustar, oír, participar. La demanda de que la experiencia turística se traduzca también en una vivencia creativa de ocio requiere, por lo general, la participación activa del visitante o turista. Por ello, es importante considerar las diferentes posibilidades de participación del turista según sus condiciones particulares: edad, limitaciones físicas, formación previa, nacionalidad y procedencia cultural, intereses específicos, disponibilidad económica, etc. A su vez, la demanda de turismo cultural con respecto a un ocio creativo también puede verse diversificada en función del tipo de agrupamiento en el que se presenta el turista cuando accede al destino. Así, encontramos grupos de personas mayores o de la tercera edad, grupos escolares, familias con niños pequeños, grupos de jóvenes, etc., cuyas necesidades y posibilidades requieren una atención educativa específica. 
La pedagogía se ocupa de buscar pautas para mejorar la acción y a las personas que la desarrollan, por lo que, entendemos que para lograr atender las demandas de los visitantes con sus cometidos específicos, la experiencia educativa de ocio, tendría que resultar a los turistas:

- Rigurosa, exacta, precisa, basada en datos veraces, ciertos y contrastados; al menos esta tendría que ser la aspiración de la actividad ofertada y demandada, en clave pedagógica. De lo contrario cabría hablar de experiencia turística, incluso de ocio, pero ¿educativa?

- Amena, agradable, placentera. La disposición del turista ante los recursos y elementos culturales que pretende conocer, descubrir o sentir estaría no tanto vinculada a actividades académicas o de estudio si no a experiencias próximas al juego pedagógico, a hacer algo con alegría y con el sólo fin de entretenerse y divertirse, pero con el valor añadido de la satisfacción, el aprendizaje y el enriquecimiento personal.

- Auténtica, en el sentido más coloquial del término, como una vivencia honrada, fiel a sus orígenes. Una interpretación auténtica del patrimonio cultural es aquella que se funda en la identidad cultural local sin deformarla ni alterarla (aunque sí pueda re-crearla) y eso es lo que busca el turista cultural que quiere aprender.

- Diferente: las experiencias educativas de turismo cultural buscan a la vez ser "moción" y "emoción", esto es atraer, mover al turista hacia el descubrimiento del bien patrimonial, pero también emocionar, alterar positivamente el ánimo del visitante para que se implique y participe, expectante, en la experiencia de aprendizaje.

No cabe duda de que es difícil que todas las situaciones de turismo cultural reúnan simultáneamente las condiciones recién enumeradas, que deben ser vistas más bien como una aspiración a alcanzar cuando con la vivencia turística se pretenda, también, un enriquecimiento personal del visitante.

\section{Turismo Cultural como oferta educativa}

En este apartado, cabría hablar de la propia actividad turística como negocio: gestión de espacios culturales, interpretación de patrimonio, visitas guiadas, escenificaciones o teatralizaciones históricas, exposiciones, centros de interpretación, museos,... que dan pie a explicar un monumento, montajes escénicos que emplean música, iluminación, nuevas tecnología para dar a conocer un sitio patrimonial, un edificio emblemático, un episodio de cultura intangible, un evento especial, un personaje real o mítico, una tradición ancestral, una batalla, un tipo de comida, un hecho histórico... sin embargo y desde la perspectiva de la educación, no nos centraremos en las diferentes maneras didácticas de presentar estos recursos si no 
en el interlocutor del turista, el profesional que asume la tarea de enseñar ese patrimonio. Para que su labor tenga carácter educativo, estos profesionales tendrían que ambicionar cumplir unos requisitos mínimos.

El perfil profesional que propone O. Fontal (2003: 201) basado en su modelo de educación patrimonial propone una formación específica y al mismo tiempo general, vinculada a las teorías y técnicas de la educación.

"La solución pasa por una formación equiparada y sólida en ambas dimensiones. Ahí reside, precisamente, el carácter de especialización del educador patrimonial. De la misma manera que una formación sólida en fundamentos y metodología educativa no es suficiente sin un conocimiento igualmente sólido de las disciplinas culturales, no es posible pretender que exista un educador patrimonial muy cualificado en el dominio de conocimientos vinculados a la cultura si desconoce la realidad educativa. Por otra parte, pretendemos evitar la reducción de la formación educativa al ámbito metodológico y abogamos por una formación teórico-práctica, que permita una comprensión integral de la realidad educativa” (Fontal, 2003: 201).

Por tanto, se nos presentan, al menos, dos exigencias fundamentales para que un profesional turístico esté preparado en educación patrimonial, que tenga conocimientos culturales y educativos. Esto es,

- Competencia técnica referida a los rasgos, características y peculiaridades que definen el elemento de turismo cultural concreto: conocimientos y capacidad de interrelación entre conceptos de arte, cultura, patrimonio, historia, sociología... Además, el profesional debe dominar y ser capaz de aplicar estos conocimientos al caso o al objeto concreto al que se refiere la actividad turística y poder establecer interrelaciones entre estos conceptos en esa situación peculiar.

- Competencia pedagógica para tratar adecuadamente el elemento de turismo cultural de tal manera que la actividad se convierta en experiencia educativa de ocio: dominio de las acciones educativas que permitirán al profesional dar a conocer el recurso, describirlo, mostrarlo, enseñarlo en el doble sentido de exponer ante el público las señas de identidad del recurso para que sea visto y apreciado (señalarlo) y en el de guiarle para que desde esa exposición pueda entender otras experiencias (educarlo).

En este sentido, es recomendable que el profesional del turismo cultural conozca, sea habilidoso y diestro en el manejo de tres acciones educativas: información, formación y animación.

El término información deriva de la palabra latina informatio que significa “imagen” (Rodríguez, 1991: 47-48). Es, en esencia, un conjunto de datos, enunciados o afirmaciones que se presenta con certeza. Cuando la 
veracidad de una afirmación no está demostrada se concibe como un valor o una opinión (Sánchez, 1991: 63).

Existe diferencia entre la información turística y la información como contenido cultural de la experiencia educativa de ocio. La información turística es el conjunto de servicios que se ofrecen al turista con el objetivo de orientarle, facilitarle y atenderle durante su viaje o estancia vacacional. Se trata, específicamente, del conjunto de datos y orientaciones que afectan a la logística del viaje y que abarcan referencias, horarios, sistemas de acceso, empresas, contactos, gestión de entradas para acceder a recursos y actividades culturales como monumentos, museos, espacios rurales, lugares de interés turístico, ferias, congresos y festivales; información y orientación sobre actividades turísticas, culturales, recreativas, deportivas y de ocio o esparcimiento a las que el visitante puede tener acceso durante su estancia en la zona; servicios de interés general sobre comercios, entidades financieras, farmacias, transportes, centros médicos que puedan facilitar su estadía; alojamientos, restaurantes, y todo lo que se puede precisar para una visita confortable en el punto de destino.

Mientras que en el turismo cultural, y durante el espacio de tiempo que dura la experiencia pedagógica de ocio, el público reclama otro tipo de información mucho más específica referida al propio recurso mostrado, relacionada con su singularidad cultural: fechas, historia, anécdotas, características, explicación de procesos, etc.

Los datos nutren la comunicación entre quien busca conocer un elemento del patrimonio cultural y quien lo muestra. Así, pues, la comunicación social es la transmisión de información (señales, símbolos) de una fuente informativa (emisor, comunicante -el profesional-) a un receptor de información (destinatario, receptor -el turista-).

Además de contenido de comunicación, la información es un instrumento de motivación. Los turistas se sienten atraídos y motivados por temas directamente referidos a su realidad, a su medio más inmediato o a las relaciones que se establecen entre ellos, por un lado y entre ellos y el medio visitado, por otro. Esto es, se sienten motivados cuando encuentran significativa la información que les aporta el profesional. Y es que por lógica, el valor motivador y motivante de la información se verá altamente reforzado si a la proximidad de la vivencia personal se unen el aprendizaje y posterior empleo de esa información.

Así es como también la información se presenta como un vehículo o cauce de formación. Informar no basta, es preciso que en su intervención, el profesional, procure que cada individuo no sólo reciba datos sino que además aprenda a seleccionar los más sugerentes, los que induzcan al visitante a continuar explorando, conociendo, aprendiendo cosas sobre ese recurso, ese tema... Y, en general, como acción educativa, la información prepara a los individuos para la actuación en su propio proceso de mejora (Sánchez, 1991: 12). 
La calidad de una experiencia de turismo cultural no depende sólo de suministrar muchos datos al visitante. Se deben incluir también auxiliares que ayuden al turista a organizar la información y relacionarla con lo previamente almacenado. Es necesario situar cada nuevo contenido en un conjunto más amplio y presentar su relación con otros datos más próximos para facilitar la conexión y la integración entre ellos. Además, debe presentarse la información a un ritmo que permita su adquisición, teniendo en consideración las peculiaridades de los interlocutores.

No toda información es válida; resulta obligado seleccionar entre muchos datos, aquellas informaciones que resulten pertinentes y motivantes para la experiencia turística.

Pensando en el profesional del turismo cultural, protagonizar la información o saber informarse adecuadamente (para luego ser capaz de informar) respecto a cualquier realidad requiere reconocer la importancia de una serie de capacidades básicas, como son la comprensión lectora, la capacidad de observación y la capacidad de escuchar, que permitirán cubrir una serie de objetivos: saber recopilar información; saber seleccionarla; saber aplicarla a circunstancias concretas; saber objetivar la información, separándola de la opinión personal; y actualizarla (Rico, 1992: 15$16)$.

Saber informarse debe significar, aclarar los ámbitos alrededor de los cuales le conviene recibir información al turista y establecer las áreas de interés para la recogida de datos. Cuando no se delimitan estos aspectos es posible que la cantidad y la calidad de la información recogida y mostrada no esté suficientemente sistematizada, sea pobre o demasiado abundante, demasiado concreta o excesivamente general.

Aprender a informarse implica, además, huir de los propios prejuicios, diferenciar entre hechos y opiniones, distinguir entre lo importante y lo secundario, reconocer fuentes fiables, adquirir información completa y tener capacidad de recuerdo.

Aprender a informarse también implica aprender dónde y cómo encontrar la información, cómo utilizar los medios y sistemas tecnológicos de comunicación más avanzados.

Como segunda acción educativa a desarrollar por el profesional del turismo cultural, íntimamente ligada a la información, aparece la formación.

Formar es más que ofrecer conocimientos, supone enseñar a guiarse entre ellos, a ordenarlos, a clasificarlos, a estructurarlos (Marzo y Figueras, 1990: 6). Se convierte en un medio para que cada persona consiga transformaciones (Palazon, 1992: 59), con objetivos hondos y consistentes, en un plano individual y social. En el turismo cultural, la formación que se ofrece al visitante tiene un carácter no formal o informal; uno casi no nota que aprende, pero poco a poco, a partir de los datos ofrecidos, el turista es 
capaz de extrapolar los conceptos e informaciones adquiridas a otras experiencias, se interroga sobre el elemento cultural visitado o incluso es capaz de cuestionar los argumentos interpretativos del profesional a la luz de otros conocimientos que el mismo posee.

Finalmente, como tercera acción educativa aparece la animación. Etimológicamente, este término hace referencia a la acción que infunde vida, da ímpetu, es un actuar sobre algo, o también incitar y motivar para la acción compartida. Su significado compuesto procede de una doble raíz latina con trasfondo griego: animación como ánima: vida, sentido, dar espíritu o aliento. Y animación como animus: motivación, movimiento, dinamismo. Esta doble dimensión semántica genera dos acciones “dar vida” o “poner en relación” que se complementan en la práctica (Froure y Quintas, 1990: 30-31). La animación es una, mientras que la vivencia de animación es lo que cambia, de "ser animado" a “estar animado” o "animarse”.

Se puede establecer que la animación se presenta, en primer lugar, como motivación. Proporciona una razón, una causa, una ocasión para actuar. En este contexto, se puede definir la motivación "como el conjunto de elementos o factores que están activamente presentes, en un momento dado en la conciencia del ser humano y que configuran la fuerza psíquica y los mecanismos de estímulo que conducen a la acción” (Ander-Egg, 1989: 242).

Esos posibles elementos motivantes y motivadores se agrupan en factores internos (necesidad, instinto, aspiraciones) o externos (valor del objeto o de un logro) que intervienen en la elaboración de una intención, dando motivo, razón adecuada, estímulo suficiente y energía necesaria para inducir a una acción deliberada y voluntaria, encaminada a satisfacer alguna necesidad individual o social.

En todo proceso de motivación intervienen dos elementos destacados: el valor y la expectativa. El valor depende de la importancia que cada individuo da a las cosas o a los resultados conseguidos, según sus propias opciones: ¿Por qué vale la pena hacer esta actividad turística? ¿vale la pena aunque suponga desembolso de tiempo, energía y dinero?

Por su parte, la expectativa es la posibilidad que ve el individuo de realizar algo con confianza en su eficacia y éxito: ¿Puedo, realmente, hacer esto? Valor y expectativa unidos dan una alta motivación. En muchas ocasiones, el turista valora muy positivamente el elemento cultural a conocer pero no se decide a visitarlo. Entonces, son interesantes los incentivos o refuerzos externos que hagan ver la importancia, el interés o la satisfacción que se logrará realizando la actividad propuesta. Y, aquí entraríamos en otro área de contenidos importantes para una actividad turística: el marketing, las técnicas de comercialización, difusión o propaganda... que exceden el contenido de este análisis.

En general, en los procesos turísticos la motivación incluye tres pasos: 
- aparición del motivo: una necesidad, apetencia, curiosidad, moda por acercarse a determinado patrimonio cultural para conocerlo,

- conducta consiguiente: el turista calibra sus expectativas y decide en consecuencia, qué destino elegir, y dentro de éste qué actividades desarrollar y cuáles no. La conducta generada tras la aparición del motivo es instrumental ya que tiende a reducir o satisfacer la necesidad del turista -el motivo- y alcanzar su objetivo -la satisfacción de esa necesidad-,

- y acción final: una combinación de variables que van desde el análisis y estudio de las opciones existentes, del tiempo disponible, del conocimiento de las ofertas del destino, de los condicionantes económicos, del gusto del visitante, de su edad, de la dificultad y accesibilidad de la actividad, etc. dará lugar a la elección del turista.

De forma consciente o inconsciente, las motivaciones están en el inicio de cualquier actividad turística, cultural o no, y es lo que induce al viajero a elegir un destino u otro, un contenido, una visita o un evento en lugar de otro.

Obviamente, además de motivación, tras la decisión del turista y su elección de una actividad concreta, se requiere otra vertiente de la animación: la intervención; este concepto nos devuelve, por un lado, al hecho de que el profesional del turismo cultural "debe dar vida” (re-crear) al recurso para que la experiencia sea gratificante, enriquecedora y atractiva para el visitante; y por otro, a la idea de que la participación activa del público es conceptualmente, una de las características distintivas de los procesos de turismo cultural. Esta participación, en la práctica, no se produce de forma espontánea; necesita ser enseñada y ser aprendida, es decir, "para que las personas participen en una actividad es indispensable incitarles" (Jor, 1975: 102). Este incitar se asimila a animar.

En este sentido, se caracteriza la animación por ser un

"conjunto de técnicas sociales que, basadas en una pedagogía participativa, tiene por finalidad promover prácticas y actividades voluntarias que, con la participación activa de la gente, se desarrollen en el seno de un grupo o comunidad determinada. La animación se manifiesta en los diferentes ámbitos del desarrollo de la calidad de vida. Más que por sus tareas concretas y actividades específicas, la animación se caracteriza por la manera de llevarlas a cabo. No es un sector aparte, sino un modo de realizar el conjunto de actividades sociales; se trata de encontrar formas y proyectos que realmente animen a los ciudadanos a participar en la vida social. Por eso, en cuanto metodología no tienen tanto la finalidad de promocionar y difundir cultura (aunque eso también lo hace) cuanto de promover un conjunto de prácticas y de actividades destinadas a generar procesos de participación cultural en el mayor número posible de personas” (Quintana y otros, 1985: 197). 
De tal modo que cabe afirmar que un educador patrimonial que se dedique al turismo debe ser un animador cultural.

Y, aunque aquí concibamos la experiencia desde un punto de vista pedagógico, el profesional del turismo cultural tendría que ser consciente de que asume la dirección de una actividad lúdica y de tiempo libre, para la que resulta conveniente alcanzar un cierto grado de:

- Competencia tecnológica, es decir, capacidad para emplear, si fuera necesario, herramientas técnicas (nuevas tecnologías, megafonía, iluminación, audiovisuales, técnicas teatrales, técnicas de imagen, etc.) para que la actividad sea novedosa, estimulante y atractiva también en su formato de presentación y no sólo en su contenido.

- Empatía, psicología y habilidades sociales: cualquiera que sea el formato elegido para mostrar el elemento cultural, e incluso, sea cual fuere ese recurso turístico, estamos ante una experiencia vital de relación humana, de comunicación. En ella, se establece una conexión estrecha, personal y directa entre quien quiere conocer y aprender de la experiencia y quien ofrece la enseñanza cultural. Por lo general, se trata además de actividades de índole colectiva, grupos que pueden ser muy variados entre sí, que pueden venir con experiencias previas (ya sean positivas o negativas) y que tienen sus propios intereses y preferencias, por lo que las fórmulas mecanizadas, uniformes o estandarizadas a la hora de enseñar los recursos del turismo cultural suelen fracasar. Ante cada grupo, el profesional, para generar una experiencia educativa, tendría que estar preparado para hacer un ejercicio de empatía; para, al menos intuir cuál es la situación en que se encuentre y el interés principal de su público y adaptar su mensaje a ello. Para llegar a empatizar con su público el primer paso a dar por el profesional es aprender a escuchar adecuadamente, dejando constancia correcta de lo escuchado. La escucha es una capacidad que debe ser intencionalmente enseñada y estimulada en procesos que como el turismo cultural se basan en la comunicación entre personas. Una de las características diferenciales de un turismo cultural que pretenda llegar a ser experiencia educativa es su capacidad de cercanía vital, la posibilidad de atender a la demanda real del público de forma empática, lo cual sólo puede hacerse escuchando (Escarbajal, 1992). Escuchar significa aquí, oír, atender, comprender, investigar y asimilar lo que el otro quiere decir o quiere aprender.

- Asimismo, cada grupo de visitantes se diferencia de otro por las características físicas, psicológicas y emocionales de las personas que lo integran, por lo que el profesional del turismo tendría que poseer conocimientos de psicología para adaptar su lenguaje, el guión de su discurso e incluso la metodología de su exposición o actividad a las necesidades y peculiaridades de sus receptores. Finalmente, 
otro aspecto importante, en el que los profesionales requieren competencias especiales tiene que ver con la forma de transmitir, difundir y exponer los contenidos que encierra el elemento cultural, adoptando siempre las máximas precauciones para tratar al grupo de visitantes con la mayor corrección, con afabilidad pero con respeto hacia formas de entender, ideologías, creencias diferentes a las propias... exigiendo al mismo tiempo que se respeten las peculiaridades, características y orientaciones del lugar, evento o episodio cultural abierto al turista.

- Versatilidad y capacidad de improvisación: por lo general, las actividades de turismo cultural (ahí radica su carácter y valor de vivencia diferenciada, abierta y natural) son "en vivo y en directo", cara a cara con el público y en cada actuación, los profesionales deben dominar habilidades para subsanar imprevistos: climatologías adversas; horarios que no se cumplen estrictamente y que hace que los grupos se retrasen o adelanten; programas de contenidos muy monótonos que pueden conducir a que el grupo se muestre apático, poco receptivo o desmotivado; cansancio en los viajeros por programas demasiado exhaustivos, etc. Todas estas circunstancias se presentan ante el profesional de repente y siempre de un modo distinto porque cada grupo es único, por lo que su solución no puede estar preparada de antemano... sin embargo, se debe tener, la habilidad inmediata, casi, espontánea de solucionar estas cuestiones.

- Capacidad de acogida: el profesional del turismo cultural no es un mero guía, lo que buscan encontrar en él los visitantes es alguien que les acoja, que sepa transmitirles la emoción que siente por ser parte de ese lugar o de ese evento... y que tras compartir unos minutos, incluso horas y días con el visitante, la relación que han entablado pase de ser profesional a amistosa. En este sentido, traemos aquí una cita de Ezequiel Ander Egg que resume perfectamente esta idea: "Cada persona, en lo más profundo, siente necesidad de ser tratada como ‘alguien', no como “algo”, como un “objeto”. Cada uno de nosotros lo experimentamos: nos sentimos como personas, cuando los otros nos tratan como centro de dignidad y valor” (Ander-Egg, 1989: 176).

\section{Los beneficios del Turismo Cultural como actividad de ocio creativo para la población local}

Además de los profesionales, desde la oferta de turismo cultural, existen otros actores (a veces secundarios y no siempre receptivos) que pueden vivir también estas actividades con perspectiva educativa. Nos referimos a la comunidad en la que se encuentra el bien o recurso patrimonial objeto de la intervención turística. Añadimos, de esta manera, una clave nueva para el análisis, la de considerar el turismo cultural desde su contri- 
bución al desarrollo local de la comunidad anfitriona. Y, desde la posición de la población receptora del turista y propietaria del elemento cultural, son muchos los autores que señalan ventajas pedagógicas como:

- "puede contribuir a generar una toma de conciencia con relación a la preservación del patrimonio, tanto tangible como intangible, comprendiendo que éste es la herencia que lo distingue y le otorga individualidad" (Toselli, 2006: 177)

- Recupera y revitaliza la cultura local: reactiva el interés de los habitantes por su cultura, expresada a través de sus costumbres, artesanías, folklore, fiestas, gastronomía, tradiciones, así como en la protección del pat

- Potencia el sentido de identidad de la comunidad.

- Contribuye a mantener la diversidad cultural: entendida ésta como una fuerza motriz del desarrollo, no sólo en lo que respecta al crecimiento económico, sino como medio de tener una vida intelectual, afectiva, moral y espiritual más enriquecedora.

- Simultáneamente, el reconocimiento de la diversidad cultural -mediante una utilización innovadora de los medios y de las nuevas Tecnologías de la Información y la Comunicación en particularlleva al diálogo entre civilizaciones y culturas, al respeto y a la comprensión mutua.

- Potencia la autoestima de la comunidad y las actividades colectivas.

- Ayuda a la identificación y al conocimiento del lugar.

- Proporciona oportunidades de intercambio cultural entre los residentes locales y los nuevos llegados, en la medida en que promueve la comprensión y entendimiento entre los pueblos, a partir de un conocimiento más profundo de la comunidad anfitriona por parte de los visitantes y viceversa. Por lo tanto, mayor tolerancia y respeto hacia otras costumbres, lo que evitaría fenómenos racistas y xenófobos. Gran parte de muchos malentendidos culturales surgen de la ignorancia de éstos; el acercarse a ellos, conocer sus razones, verlos directamente e incluso compartirlos puede generar una mayor tolerancia entre los foráneos. Un turista que ha crecido con estereotipos puede tener un cambio de paradigmas cuando conoce una cultura distinta.

- Fortalece el desarrollo de políticas y programas conjuntos entre el sector turístico y el cultural.

- Genera recursos para el mantenimiento, protección, conservación y mejora de los sitios patrimoniales. 
- Se recupera la herencia de los antepasados que se integra en proyectos de desarrollo a través del turismo.

Al igual que con otros planteamientos hechos más arriba cabría, ante esta enumeración de ventajas y beneficios, iniciar un debate crítico que nos sobrepasa, por lo que dejamos abierto el tema para futuros debates que requieren un análisis transdisciplinar. Lo que es evidente es que la formación de la comunidad anfitriona tendría que ir más allá de la educación patrimonial y convertirse en educación para el desarrollo sostenible. Cuando las acciones de formación de la comunidad anfitriona para conocer y aprovechar desde el punto de vista turístico su bagaje cultural se insertan en la estrategia de desarrollo, señala Antonio Vázquez Barquero, la mejora de la calidad de los recursos humanos propicia el aumento de la productividad, estimula la competitividad, e incluso afecta al modelo cultural en el que se apoya el proceso de desarrollo (Vázquez Barquero, 2009).

Desde esta perspectiva educativa se trata de que las actividades de turismo cultural sean sostenibles, de tal manera que puedan responder a las necesidades de los turistas y de las comunidades anfitrionas del presente, a la vez que preservan y promueven oportunidades para el futuro. La actuación de la comunidad anfitriona en materia de turismo tendría que estar enfocada a un modelo de gestión de todos los recursos para que fuera posible satisfacer las necesidades económicas, sociales y estratégicas a la vez que se respete la integridad cultural, los procesos ecológicos esenciales, la diversidad biológica y los sistemas de soporte a la vida (Cánoves, Villarino y Herrera 2006). Es importante, por tanto encontrar una correcta armonía en la relación que se establece entre las necesidades del visitante, el lugar y la comunidad receptora.

Sin embargo, si la población local no aprende a mostrar y tratar su patrimonio cultural con las debidas consideraciones caben algunos riesgos y problemas:

- Artificializar la cultura local, provocando un proceso de desculturización del destino, incluso de banalización o de escenificación de la cultura.

- Alterar el equilibrio social de la comunidad.

- Provocar aculturación en la población receptora, al adoptar ésta normas y patrones culturales a través del contacto con el turista. El turismo relaciona diferentes culturas: la local o receptora con la foránea o emisora. Esto supone un intercambio de pautas de conducta, formas de vida, hábitos de diversa índole (gastronómicos, lingüísticos, estéticos,...). Este efecto, aunque positivo en ocasiones, puede llegar a ser perjudicial para la población autóctona, ya que pueden renunciar a rasgos de su identidad, mercantilizándola, al intentar adaptarse a los gustos y tradiciones del visitante. 
- El modelo de aculturación puede aplicarse al contacto entre turistas y anfitriones. Este modelo explica que cuando dos culturas entran en contacto cada una tiende a asemejarse en parte a la otra mediante un proceso de préstamo. En el caso del turismo es característico que este proceso sea asimétrico. Los turistas tienen menos probabilidades de tomar determinados elementos de sus anfitriones. Esto provoca una cadena de transformaciones en la comunidad de la zona turística para convertirse en algo cada vez más parecido a la cultura de los turistas. Durante esta interacción el turista, a menudo, altera su conducta cuando esta lejos de su lugar de procedencia y sus anfitriones aprenderán, con frecuencia, una serie de papeles destinados a encajar con los gustos de los visitantes.

- Generar sensación de usurpación de identidad y marginalización de la comunidad local.

- Provocar un sentimiento de rechazo por parte de la comunidad local cuando no se respetan lugares sagrados o costumbres propias o incluso crear inhibición cuando la comunidad siente invadido su espacio vital y se siente observado y hasta juzgado.

- Originar un sentimiento de decepción o frustración por parte de los turistas cuando no se responde a sus expectativas estereotipadas, es decir, cuando lo que esperan no se corresponde con la realidad (provocado por una falta de comunicación y difusión responsable por parte de los planificadores o tour operadores).

Aprender a conservar el medio y los recursos, atender las demandas y expectativas de los huéspedes y cumplir con los requisitos de pertenencia a una asociación y la voluntad de preservar el patrimonio paisajístico, arquitectónico, cultural y social para las futuras generaciones, la aceptación por parte de la población autóctona de la llegada de dichas actividades y los beneficios a largo plazo del turismo rural son algunos de los desafíos que tiene el implicar a la población en el diseño y propuesta de un plan de desarrollo del turismo local basado en la valorización y aprovechamiento de los recursos propios. Para que este proceso sea exitoso se debe plantear, en todo momento, como intervención-actuación educativa.

\section{Algunos retos para la reflexión}

El turismo cultural es un fenómeno social y económico complejo, cuyo análisis científico resulta también complicado en la medida en que existen algunos aspectos que deben ser abordados de forma transdisciplinar y otros que requieren la intervención de una disciplina específica. Aquí hemos intentando iniciar una reflexión desde el ámbito de la educación, centrándolo en los protagonistas de la acción turística, pero somos conscientes de que quedan muchas cuestiones sin resolver e incluso sin abrir. Apuntamos, a modo de conclusión, algunas de ellas: 
- La dificultad de proporcionar pautas y programas educativos adecuados a la realidad de cada comunidad local cuando las tendencias y las políticas se orientan a plantear programas y contenidos globalizados.

- Cómo lograr una experiencia enriquecedora a través de una vivencia turística cuando el ocio, y en especial el turismo, están cayendo dentro de parámetros eminentemente economicistas que fomentan sobre todo el consumismo y la alienación humanas.

- Cómo se puede, desde la educación, hacer reflexionar, cuestionar y encontrar pautas para mejorar las prácticas de turismo cultural, tanto desde la demanda (educación para el consumo) como desde la oferta (educación para el desarrollo sostenible), evitando orientaciones perversas. Esto, es, por un lado, cómo y dónde educar al visitante para sea capaz de seleccionar experiencias verdaderamente enriquecedoras. Y por otro, cómo, desde la comunidad anfitriona, se deben seleccionar y tratar los elementos para que no se desvirtúen su valor cultural; o dicho de otro modo, como hacer confluir y aprovechar el valor cultural, el valor patrimonial, el valor turístico y el valor pedagógico en la experiencia ofertada. Más aún, cabe plantear la necesidad de identificar a las instituciones encargadas de asumir la responsabilidad educativa tanto en el lugar de destino (profesionales del turismo cultural, otros responsables de la acogida turística, comunidad en general) como en lugar de origen, de dónde parten los visitantes al encuentro con una vivencia con aspiración de enriquecerse con ella como personas.

- Finalmente, aquí hemos abordado la cuestión pedagógica centrándonos en los actores del turismo cultural, pero quedan para el futuro pendientes otros análisis del fenómeno del turismo cultural como experiencia de ocio creativo: contenidos, metodologías, planificación, etc. 


\section{Bibliografía}

Ander-Egg, E. (1981), Metodología y Práctica de la Animación Sociocultural. Marsiega, Madrid.

Idem (1987), Autoconstrucción y ayuda mutua. El Trabajo Social en Programas de Vivienda. Humanitas, Buenos Aires.

Idem (1989), La animación y los animadores. Narcea, Madrid.

Cànoves, G.; Villarino, M., y Herrera, L. (2006), "Políticas públicas, turismo rural y sostenibilidad: difícil equilibrio" Boletín de la Asociación de Geógrafos Españoles (AGE), nº41, ${ }^{\text {er }}$ semestre, Revista Electrónica http:/ /age.ieg.csic.es/boletin

Cuenca, M. (2004), Pedagogía del ocio: modelos y propuestas. Universidad de Deusto, Bilbao.

Dumazedier, J. (1962), Vers une civilization du loisir. Editions du Seuil, Paris.

Efland, A. D.; Freedman, K; Stuhr, P. (2003), La educación en el arte posmoderno. Paidós, Barcelona.

Escarbajal De Haro, A. (1992), "El Horizonte Comunitario Como Nuevo Horizonte Educativo”. Revista de Pedagogía Social , nº 7, Valencia.

Fontal Merillas, O. (2003), La educación patrimonial. Teoría y práctica en el aula, el museo e Internet. Trea, Gijón.

Froure Quintas, S. y Sánchez Castaño, M.A. (1990), Animación Sociocultural. Nuevos Enfoques. Amarrú, Salamanca.

Hooper-Greenhill, E. (1998), Los museos y sus visitantes. Trea, Gijón.

Jor, F. (1976), Desmitificación De La Cultura: Animación Y Creatividad. Consejo De Europa, Estrasburgo.

Jover Torregrosa, D. (1990), La Formación Ocupacional Para La Inserción, La Educación Permanente y el Desarrollo Local. Popular, Madrid. Marzo, A. y Figueras, J.M. (1990), Educación De Adultos. Situación Actual y Perspectivas. Horsori, Barcelona.

Mundy, J. y Odum, L. (1979), Leisure education: theory and practice. John Wiley \& Sons Inc., New York.

Olofsson, U. K. (1979), Los museos y los niños. Servicio de Estudios y Documentación. Ministerio de Cultura, Madrid [edición original: unEsCo, 1979] 
Palazón Romero, F. (1992), “La Investigación-Acción como metodología puente entre la educación de adultos y el desarrollo comunitario”, Revista Pedagogía Social, nº 7, Valencia.

Puig i Rovira, J.M. y Trilla, J. (1987), La pedagogía del ocio. Laertes, Barcelona.

Quintana Cabanas, J.M. y Otros (1985), Fundamentos De Animación Sociocultural. Narcea, Madrid.

Rico Vercher, M. (1992), “El Aprendizaje de valores en educación ambiental”, En Varios, Unidades temáticas ambientales de la Secretaría de Estado para las políticas del agua y el medio ambiente, Ministerio de Obras Públicas y Transportes, Madrid.

Rodríguez Porras, J.M. (1991), La participación y la calidad integral. Su concepto y aplicación en empresas españolas. Universidad de Deusto, Bilbao

Sánchez Alonso, M. (1991), la participación, metodología y práctica. Popular, Madrid.

Trilla, J. (2000), “La cultura y sus mediaciones pedagógicas” en J. L. García Garrido (ed.), La sociedad educadora, pp. 215-144. Fundación Independiente, Madrid.

Toselli, C. (2006), “Algunas Reflexiones Sobre El Turismo Cultural” En Pasos Vol 4, No2 Revista de Turismo y Patrimonio Cultural, Tenerife.

UNESCO (1977), “L’UNESCO et le développement de l'éducation des adultes”, en Perspectives, VII, 2, UNESCO, Paris.

Valdés, M. C. (1999), La difusión cultural en el museo: servicios destinados al gran público. Trea, Gijón.

Vázquez-Barquero, A. (2009), “Desarrollo local, una estrategia para tiempos de crisis” en Universitas Forum Vol 1, n²2, Revista Electrónica http:// www.universitasforum.org 